\title{
Burden of Chronic Obstructive Pulmonary Disease in India: Status, Practices and Prevention
}

\author{
Md Mahbub Hossain ${ }^{1 *}$, Abida Sultana ${ }^{2}$ and Neetu Purohit ${ }^{3}$ \\ ${ }^{1}$ Nature Study Society of Bangladesh, Bangladesh \\ ${ }^{2}$ Gazi Medical College, Bangladesh \\ ${ }^{3}$ IIHMR University, India
}

Submission: March 05, 2018; Published: March 14, 2018

*Corresponding author: Md Mahbub Hossain, Nature Study Society of Bangladesh, Khulna, Bangladesh, Email: mhossa13@jhu.edu

\begin{abstract}
Chronic obstructive pulmonary disease (COPD) is affecting 251 million lives globally and it causes 3.15 million deaths per year. More than 90\% COPD-related deaths happen in low and middle-income countries. In India, three out of five leading causes of mortalities constitute noncommunicable diseases whereas COPD is the second biggest cause of death. The prevalence of COPD has increased by $29.2 \%$ by 2016 which is a serious public health concern. The clinicians require treating COPD as per the evidence-based guidelines and managing the comorbidities. To avert the cost of care, an integrated and highly efficient system is required which can promote healthier lifestyle and self-management of the symptoms through a team-based approach comprising different healthcare professionals for delivering planned care. Moreover, smoking and other risk factors should be controlled considering the future benefits of the nation. Also, air pollution and other environmental risk factors are deteriorating day by day in India that is evident in the recently published Environmental Performance Index in which India ranked fourth worst country in the world. To improve the burden of COPD, multifaceted strategies should be adopted to promote positive respiratory health in the individual and population level.
\end{abstract}

Keywords: Chronic obstructive pulmonary disease; COPD; India

\section{Introduction}

Chronic obstructive pulmonary disease (COPD) is a leading respiratory disease affecting the length and quality of lives around the globe. World Health Organization defines COPD as a lung disease characterized by chronic obstruction of lung airflow that interferes with normal breathing and is not fully reversible [1]. In 2016, there were 251 million cases of COPD in the world and it is estimated that COPD causes 3.15 million deaths per year [1]. The healthcare burden of COPD can be as high as $\$ 50$ billion in countries like US where COPD is the third leading cause of mortality [2]. Due to its association with smoking and environmental pollution, the burden is much higher in low and middle-income countries. An estimation shows that more than $90 \%$ COPD-related deaths happen in those countries and India is no exception for such a tremendous public health problem $[1,3]$. In this review, we discuss the magnitude, management practices, economic burden and preventive approaches of COPD in the context of India.

\section{Epidemiology and Magnitude of COPD in India}

With the pace of demographic and epidemiological transitions, the changes in socio-behavioral dimensions and their impacts on population health are evident. In India, the burden of all non-communicable diseases has increased since 1990 [4]. As on 2016, three out of five leading causes of mortalities constitute non-communicable diseases whereas COPD is the second biggest cause of death in India today [5]. Different studies have revealed varying range of prevalence of COPD in different states. The prevalence ranged between 2 to $22 \%$ among the men and 1.2 to $19 \%$ among women in different population-based studies across India [6]. It became fourth leading cause of years of life lost in Empowered Action Group (EAG) States including Bihar, Jharkhand, Madhya Pradesh, Chhattisgarh, Odisha, Rajasthan, Uttar Pradesh and Uttarakhand [5]. Also, COPD ranked seventh among the North-East States including Assam, Mizoram, Arunachal Pradesh, Meghalaya, Nagaland, Tripura, Sikkim and Manipur [5]. Among the remaining states of India, COPD ranked fourth among all causes of years of life lost [5]. In this varying range of disease burden, the highest rate of death from COPD was nine times the lowest rate among all the states [5]. A graphical overview of India as per the disability adjusted life years (DALYs) rate due to COPD is shown in Figure 1. 


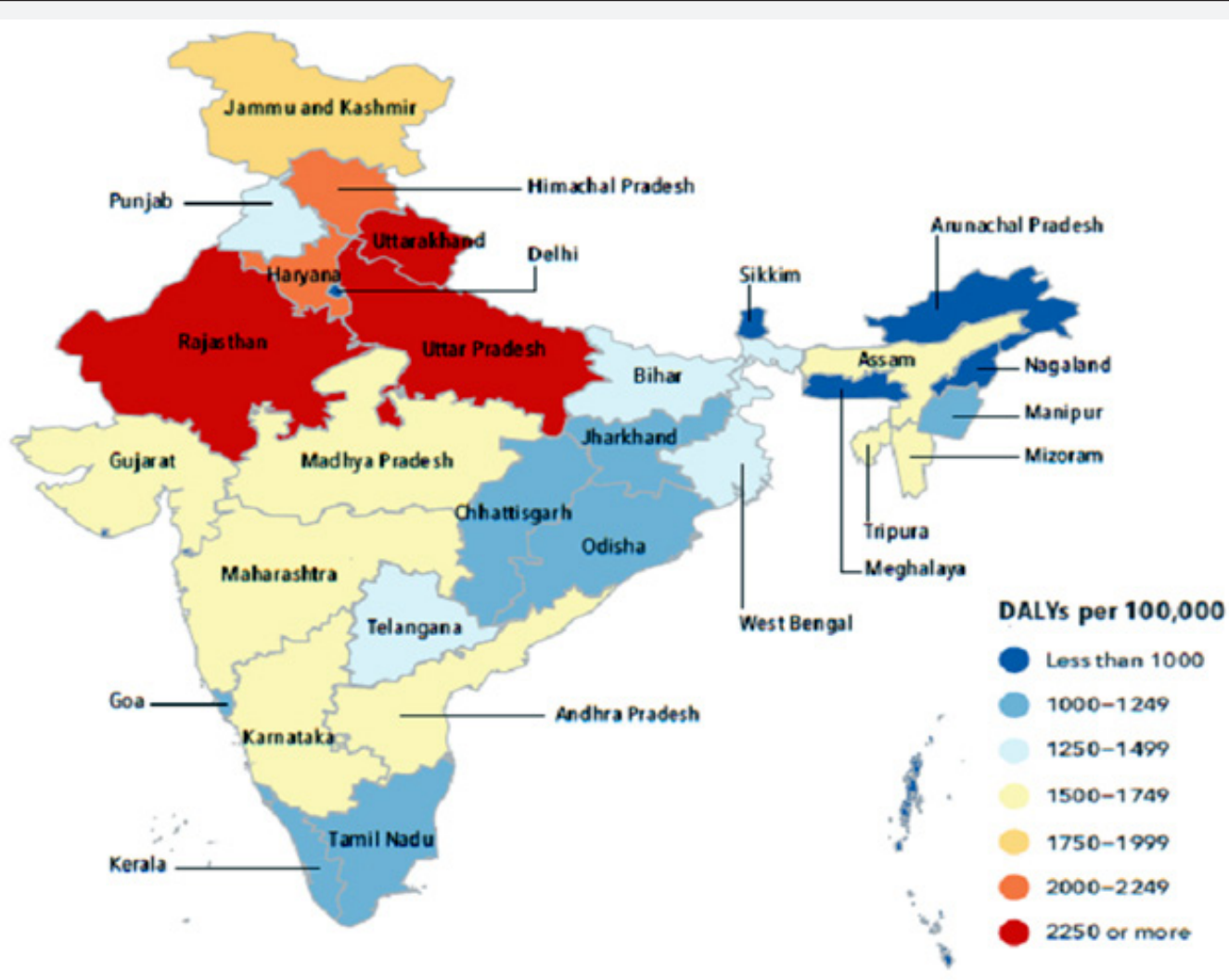

Figure 1: Geographic distribution of DALYs due to COPD per 100000 population in India [5].

In addition, COPD has been among the top eight leading causes of disabilities in all the states [5]. Comprising all these, DALYs due to COPD increased 36.3\% from 1990 to 2016 and it became second leading cause of DALYs in India followed by diarrheal disease, lower respiratory tract infections, stroke and iron deficiency anemia [5]. The prevalence of COPD has increased by $29.2 \%$ within the same period 5 which is a serious public health concern.

\section{Current Practices in Management of COPD}

Although the magnitude of COPD is very high but often the patients do not get adequate care due to discrepancies in diagnosis, differentiation from bronchial asthma and appropriate management of the disease. In clinical settings the diagnosis of COPD relies on presence of partially reversible impairment of lung function (FEV1<80\% predicted and FEV1/FVC ratio $<70 \%$ ), history of chronic progressive symptoms like cough, wheeze, dyspnea and usually history of smoking for more than twenty packet years [7]. Most patients are aged more than 40 years and are likely to attend without evidences of respiratory infections [7]. The early symptoms like cough and respiratory distress are common among the co-smokers which can be a reason of delayed diagnosis of COPD cases. These social health expectations define the stage of diagnosis and prognosis of further treatment to a greater extent [8]. Moreover, the confirmatory test requires measuring FEV1 which can help in differentiating COPD with asthma and other diseases [7,8]. Furthermore, appropriate differentiation of the severity of COPD is also essential. The Global Initiative for Obstructive Lung Diseases (GOLD) grading based on 2007 guidelines divide the COPD cases in four grades based on FEV1 percent predicted whereas 2011 guidelines stratify the cases with additional measures like quality of life and history of exacerbation [9]. Studies have revealed that 2011 version predicts exacerbations better than the earlier version but the prediction of prognosis is more reliable in the older one $[10,11]$. To diagnose the appropriate stage of COPD, the availability of spirometric tests and other essential investigations must be ensured at primary care settings in India which is the key to treat the cases at the earliest [7]. In addition, the comorbidities that are associated with COPD should also be taken care of. Among the COPD patients, cardiovascular comorbidities are often found $(75.1 \%)$ with other comorbidities like carcinoma, anxiety, mental disorders, substance abuse, musculoskeletal and connective tissue disorders $[12,13]$. The clinicians require to treat COPD and the comorbidities with a vision of improving the quality of living.

\section{Economic Burden of COPD}

Treating COPD and associated comorbidities require institutional resources and frequent hospitalization which can be costly for the individuals as well as the health system [14]. The rate of hospitalization can be four times among elderly aged more than 65 years compared to younger patients. The mean length of hospital stays for COPD ranges from 4.5 to 16 days in normal to 
intensive care [15]. For developed countries like US the direct cost of treating COPD patient was \$36 billion in 2010 and 16.4 million days of work were lost due to COPD each year which add great burden to the individual and population level [16]. There is limited data on the cost of COPD in India which requires further research to develop cost-effective strategies for addressing the problem. In the mixed health market of India, the economic and financial burden of treating diseases is not within the reach of common people and the rate of out-of-pocket expenditure among total health expenditure is $62.41 \%$ [17]. Moreover, the social structure of India does not provide adequate protection to the elderly resulting less adherence to the treatment. In such a socioeconomic context, an integrated and highly efficient system of care is required. Such a mode of care can include behavioral change education for the patient which can promote healthier lifestyle and self-management of the symptoms, a team-based approach comprising different healthcare professionals for delivering planned care, adopting nationwide diagnostic and treatment guideline for standardizing the quality of care and improving the care reporting as well as tracking mechanism through a robust clinical information system [18].

\section{Prevention of COPD: Futuristic Approaches}

Apart from therapeutic measures India must explore the opportunities to control the risk factors both at the individual and population level. Non-modifiable risk factors like increased age and past history of respiratory infections make people vulnerable to COPD which informs the individuals and practitioners to improve the health in general and avoid other critical factors as much as possible. Historically, smoking is considered as the main risk factor for COPD which has different forms in the cultural context of India. Cigarettes and other traditional forms of tobacco smoking including "hookah" and "chillum" are very common in different states of India [19]. Studies have shown that alternative forms of tobacco smoking no less harmful compared to cigarettes smoking. Another form of smoking is very common among the Indian women who use biomass fuels like cow-dung and woods for cooking foods [20]. $70 \%$ of the Indian households depend on biomass cooking and the rate goes up to $84 \%$ in the rural areas whereas very few people prefer to use clean gas or cooking options in India [21]. Biomass smoking, actively or passively, can be a leading cause of COPD among non-tobacco users [22]. However, all forms of tobacco and non-tobacco pollutants contribute to the respiratory health and their significance is evident in different studies. Tobacco use is the sixth leading risk factor attributable to all DALYs whereas air pollution is the second one [5]. Outdoor air pollution contributed to $6.4 \%$ DALYs whereas indoor air pollution caused $4.8 \%$ of the same [5]. Air pollution and other environmental risk factors are deteriorating day by day in India that is revalidated in the recently published Environmental Performance Index in which India ranked fourth worst country in the world [23]. To improve the disease burden of COPD and other diseases multifaceted strategies should be adopted to promote positive health in the individual and community level and national-level policies to address the environmental crises.

\section{Conclusion}

A chronic progressive disease like COPD reduces the lifespan and quality of life among the affected population. In addition, the lost productivity and high treatment cost can affect the nation in a broader scale. Such an alarming public health issue warrants immediate attention of the researchers and policy makers to investigate the risks in the context of India, identify the gaps in managing the patients at primary and secondary care centers, develop patient-centric comprehensive model of diagnosis and treatment, explore the opportunities to prevent the disease through modifying the lifestyles and environmental exposures that affect the quality of life. Blaming the patients for their previous exposures to risk factors and treating them with palliative care is not a cost-effective strategy in a large country like India. All the stakeholders must come forward to address the crisis and contribute to decreasing the burden of COPD in India.

\section{Authors Contributions}

The first and second author collected data and prepared the first draft. The third author critically edited the draft and contributed additional information to the same. Further, all the authors reviewed the drafts several times and finalized the manuscript.

\section{References}

1. WHO (2017) Chronic obstructive pulmonary disease (COPD). WHO, Geneva, Switzerland.

2. Banerjee ER (2014) Perspectives in inflammation biology. India pp. 148.

3. Lopez AD, Shibuya K, Rao C, Mathers CD, Hansell AL, et al. (2006) Chronic obstructive pulmonary disease: current burden and future projections. Eur Respir J 27(2): 397-412.

4. Mahal A, Karan A, Engelgau M (2010) The Economic Implications of Non-Communicable Disease for India. Health, Nutrition and Population (HNP) Discussion Paper pp. 142.

5. ICMR-PHFI-IHME (2017) India : Health of the Nation's States.

6. Jindal SK, Aggarwal AN, Gupta D (2001) A review of population studies from India to estimate national burden of chronic obstructive pulmonary disease and its association with smoking. Indian J Chest Dis Allied Sci 43(3): 139-47.

7. Calverley P, Bellamy D (2000) The challenge of providing better care for patients with chronic obstructive pulmonary disease: the poor relation of airways obstruction? Thorax 55(1): 78-82.

8. Nolan D, White P, Pearson M (1999) FEV1 and PEF in COPD management. Thorax 54(5): 468-469.

9. Bajc M, Markstad H, Jarenbäck L, Tufvesson E, Bjermer L, et al. (2015) Grading obstructive lung disease using tomographic pulmonary scintigraphy in patients with chronic obstructive pulmonary disease (COPD) and long-term smokers. Ann Nucl Med 29(1): 91-99.

10. Lange P, Marott JL, Vestbo J, Olsen KR, Ingebrigtsen TS, et al. (2012) Prediction of the Clinical Course of Chronic Obstructive Pulmonary Disease, Using the New GOLD Classification. Am J Respir Crit Care Med 
186(10): 975-981.

11. May SM, Li JTC (2015) Burden of chronic obstructive pulmonary disease: Healthcare costs and beyond. Allergy Asthma Proc 36(1) 4-10.

12. Yeatts KB, Lippmann SJ, Waller AE, Hassmiller Lich K, Travers D, et al. (2013) Population-Based Burden of COPD-Related Visits in the ED. Chest 144(3): 784-793.

13. Maleki Yazdi MR, Kelly SM, Lam SY, Marin M, Barbeau M, et al. (2018) The burden of illness in patients with moderate to severe chronic obstructive pulmonary disease in Canada. Can Respir J 19(5): 319-24.

14. Akazawa M, Halpern R, Riedel AA, Stanford RH, Dalal A, et al. (2008) Economic burden prior to COPD diagnosis: A matched case-control study in the United States. Respir Med 102(12): 1744-1752.

15. Dalal AA, Shah M, D'Souza AO, Rane P (2011) Costs of COPD exacerbations in the emergency department and inpatient setting. Respir Med 105(3): 454-460.

16. (2014) CDC reports annual financial cost of COPD to be $\$ 36$ billion in the United States - American College of Chest Physicians.
17. (2014) World Bank. Out-of-pocket health expenditure (\% of total expenditure on health).

18. Adams SG, Smith PK, Allan PF, Anzueto A, Pugh JA, et al. (2007) Systematic Review of the Chronic Care Model in Chronic Obstructive Pulmonary Disease Prevention and Management. Arch Intern Med 167(6): 551-561.

19. Singh S, Soumya M, Saini A, Mittal V, Singh UV, et al. (2011) Breath carbon monoxide levels in different forms of smoking. Indian J Chest Dis Allied Sci 53(1): 25-28.

20. Hu G, Zhou Y, Tian J, Yao W, Li J, et al. (2010) Risk of COPD From Exposure to Biomass Smoke. Chest 138(1): 20-31.

21. Bhattacharya (2011) Overview of the Clean Cooking Challenge. Presentation Outline p. 20.

22. Terzikhan N, Verhamme KMC, Hofman A, Stricker BH, Brusselle GG, et al. (2016) Prevalence and incidence of COPD in smokers and nonsmokers: the Rotterdam Study. Eur J Epidemiol 31(8):785-792.

23. (2018) Yale University. 2018 Environmental Performance Index Global metrics for the environment: Ranking country performance on highpriority environmental issues.

\section{Your next submission with Juniper Publishers will reach you the below assets}

- Quality Editorial service

- Swift Peer Review

- Reprints availability

- E-prints Service

- Manuscript Podcast for convenient understanding

- Global attainment for your research

- Manuscript accessibility in different formats ( Pdf, E-pub, Full Text, Audio)

- Unceasing customer service

Track the below URL for one-step submission https://juniperpublishers.com/online-submission.php 